\title{
International, multicenter retrospective trial comparing the efficacy and safety of bi-flanged versus lumen-apposing metal stents for endoscopic drainage of walled-off pancreatic necrosis
}

\author{
Ali Siddiquia, Mariam Naveed', Jahangeer Bashab, Sundeep Lakhtakiab, Jose Nietof, Janak Shah", \\ Kenneth Binmoellerg, Megan Murphya ${ }^{a}$, Rupjyoti Talukdar', Mohan K. Ramchandani ${ }^{b}$, Zaheer Nabi ${ }^{b}$, \\ Rajesh Guptab, Thomas E. Kowalskie, David E. Lorena ${ }^{\text {, }}$ Reem Z. Sharaihae, Michel Kahalehe, \\ Patrick Ten Eyckc, Arish Noor ${ }^{\mathrm{a}}$, Tayebah Mumtaz ${ }^{\mathrm{a}}$, Rakesh Kalalalab, Nageshwar D. Reddy, \\ Douglas G. Adler ${ }^{\mathrm{d}}$
}

Thomas Jefferson University, Philadelphia, PA, USA; Asian Institute of Gastroenterology, Hyderabad, India; University of Iowa, Iowa City, IA, USA; University of Utah, Salt Lake City, UT, USA; New York Presbyterian Hospital, Weill Corner Medical Center, NY, USA; Borland-Groover Clinic, Jacksonville, FL; California Pacific Medical Center, San Francisco, CA, USA

\section{Abstract}

Background To compare fully covered bi-flanged metal stents (BFMS) and lumen-apposing metal stents (LAMS) for endoscopic ultrasound (EUS)-guided drainage/debridement of pancreatic walled-off necrosis (WON).

Methods Patients with WON managed by EUS-guided therapy were divided into those who underwent: 1) drainage using BFMS; and 2) drainage using LAMS and scheduled direct endoscopic necrosectomy (DEN). Clinical success (resolution of the WON), technical success (successful stent placement), and adverse events (AEs) were evaluated.

Results 387 patients underwent WON endoscopic drainage, 205 using BFMS and 182 using LAMS. The clinical success in the BFMS or LAMS groups were similar (197 [96.1\%] vs. 174 [95.6\%]; $\mathrm{P}=0.81$ ). Median number of procedures required for WON resolution was significantly lower in BFMS compared to LAMS (2 vs. 3, $\mathrm{P}<0.001)$. Technical success for stent placement was similar in BFMS and LAMS groups (203 [99\%] vs. 180 [99\%], P=0.90). Procedure-related AEs were similar in the BFMS and LAMS groups (19 [9.3\%] vs. 20 [10.9\%], P=0.61). Stent dysfunction with occluding debris was higher in the BFMS group compared to LAMS group (21 [10.2 \%] vs. $11[5.9 \%], \mathrm{P}=0.04)$. The migration rate was higher in the BFMS group than in the LAMS group (15 [7.3\%] vs. 3 [1.6\%]; $\mathrm{P}<0.001)$. DEN was required in 23 [11.2\%] patients in the BFMS group after lack of WON resolution by conservative means.

Conclusion BFMS with a "step-up approach" and LAMS with scheduled DEN are both safe and effective for EUS-guided drainage/debridement of WON.

Keywords Pancreatic walled off necrosis, acute pancreatitis, bi-flanged metal stents, lumenapposing metal stents, endosonography

Ann Gastroenterol 2021; 34 (1): 1-9
Correspondence to: Douglas G. Adler MD, FACG, AGAF, FASGE, Professor of Medicine, Director, GI Fellowship Program,

Gastroenterology and Hepatology, University of Utah School of Medicine, Huntsman Cancer Center, 30N 1900E 4R118, Salt Lake City,

Utah 84132, USA, e-mail: Douglas.adler@hsc.utah.edu

Received 15 December 2019; accepted 10 September 2020; published online 4 January 2021

DOI: https://doi.org/10.20524/aog.2021.0570

\section{Introduction}

Endoscopic ultrasonography (EUS)-guided drainage via transmural stents is increasingly considered first-line therapy in the management of symptomatic pancreatic fluid collections (PFCs) $[1,2]$. In the context of walled off necrosis (WON), a mature encapsulated collection of pancreatic necrosis that contains both liquid and solid components, transmural drainage alone may be 
inadequate and endoscopic necrosectomy may be required [3-6]. Transmural direct endoscopic necrosectomy (DEN) after stent placement involves drainage and endoscopic debridement of the WON through the gastric or duodenal wall. Several studies have demonstrated that this approach is superior to surgical necrosectomy and percutaneous catheter drainage, with superior outcomes, fewer adverse events and lower healthcare costs $[7,8]$.

Historically the placement of multiple double pigtail plastic stents (DPTs) has been the mainstay of therapy for endoscopic management of WON with regard to access and drainage. However, their use is limited by their small caliber lumen, cumbersome delivery system and consequent loss of patency, requiring the need for multiple stent placement and revisions [9-11]. Furthermore, in cases where DEN is necessary, balloon dilation of the tract is required to allow passage of endoscope into the collection for each necrosectomy session [12].

Two novel fully covered self-expanding metal stents have been designed specifically for the treatment of PFCs: the lumen-apposing metal stent (LAMS) (AXIOS ${ }^{\mathrm{m}}$ Stent; Boston Scientific Corporation, Marlborough, MA), with both proximal and distal anchor flanges, and the bi-flanged metal stent (BFMS) (NAGI stent; Taewoong Medical Co., Ltd., Goyang, Korea). Both LAMS and BFMS have high reported rates of technical (89-100\%) and treatment success (93-100\%) in the management of symptomatic PFCs [13-19].

The aim of our study was to evaluate the efficacy and safety of fully covered self-expanding BFMS and LAMS for EUSguided drainage/debridement of pancreatic WON.

\section{Patients and methods}

\section{Patients}

The endoscopy databases at 5 tertiary centers were queried for all patients who had undergone EUS-guided drainage/

${ }^{a}$ Thomas Jefferson University, Philadelphia, PA, USA (Ali Siddiqui, Megan Murphy, David E. Loren, Arish Noor, Tayeban Mumtaz); ${ }^{\text {} A s i a n ~ I n s t i t u t e ~ o f ~}$ Gastroenterology, Hyderabad, India (Jahangeer Basha, Sundeep Lakhtakia, Rupjyoti Talukdar, Mohan K. Ramchandani, Zaheer Nabi, Rajesh Gupta, Rakesh Kalalala, Nageshwar D. Reddy); 'University of Iowa, Iowa City, IA, USA (Mariam Naveed, Patrick Ten Eyck); 'University of Utah, Salt Lake City, UT, USA (Douglas G. Adler); ${ }^{\mathrm{e} N e w}$ York Presbyterian Hospital/Weill Cornell Medical Center, New York, NY, USA (Thomas E. Kowalski, Reem Z. Sharaiha, Michel Kahaleh); ${ }^{\mathrm{f} B o r l a n d-G r o o v e r}$ Clinic, Jacksonville, FL,

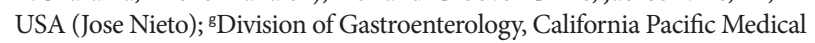
Center, San Francisco, CA, USA (Janak Shah, Kenneth Binmoeller)

Drs. Siddiqui and Naveed had equal contributions and request to be considered as joint first authors

Conflict of Interest: Ali Siddiqui: Consultant Boston Scientific, Medtronic, AbbVie; Jose Nieto: Consultant Boston Scientific, Medtronic; Janak Shah: Consultant Boston Scientific, Medtronic; Kenneth F. Binmoeller: Consultant Boston Scientific, Developer of the AXIOS stent with Xlumena; Thomas Kowaski: Consultant Boston Scientific, Medtronic, Cook Medical; David Loren: Consultant Boston Scientific, Medtronic, Cook Medical; Douglas G. Adler: Consultant Boston Scientific, Medtronic, Merit; Reem Z. Sharaiha: Consultant Boston Scientific, Apollo; Michel Kahaleh: Consultant Boston Scientific; Nageshwar D. Reddy;

Developed the Nagi stent with Taeewong Endoscopy debridement of a pancreatic WON between November 2009 and December 2015. Only patients with a 6-month or greater follow up were included in the study.

We included patients who had a pancreatic WON, demonstrated by computed tomography (CT) or magnetic resonance imaging, with the following symptoms: 1) refractory abdominal pain; 2) gastric outlet or biliary obstruction; 3) ongoing systemic illness, anorexia, and weight loss; 4) rapidly enlarging WONs; and/or 5) infected WONs. A pancreatic WON was defined as a mature, encapsulated collection of pancreatic and/or peripancreatic necrosis that had developed a well-defined inflammatory wall (as per the Revised Atlanta Classification) [4].

Patients at the Asian Institute of Gastroenterology underwent therapy with BFMS. Patients at Thomas Jefferson University, University of Utah, New York Presbyterian Hospital, BorlandGroover Clinic, and California Pacific Medical Center underwent therapy with LAMS.

We excluded patients who had pancreatic pseudocysts, neoplastic cystic lesions, coagulopathy (international normalized ratio $>1.5$ ) and thrombocytopenia (platelets $<50,000 / \mathrm{mm}^{3}$ ), or imaging showing that the WON wall was not in close contiguity $(>2 \mathrm{~cm})$ to the EUS probe.

\section{Procedure and technique}

\section{Initial endoscopic drainage of the WON cavity}

All patients underwent endoscopy using a linear array echoendoscope under monitored anesthesia care or general anesthesia. Patients were administered broad-spectrum antibiotics before and after the procedure. The echoendoscope was used to examine the site of the WON. EUS imaging under Doppler flow guidance was used to assess local vasculature and determine the cyst puncture site (either trans-gastric or transduodenal). A 19-G needle was used to perform the primary puncture into the WON cyst cavity. The contents were then aspirated to confirm the location and the aspirate was sent for microbiology. A 0.025 " or 0.035 " guidewire was inserted through the needle and then coiled into the PFC. The needle was then withdrawn, leaving the guidewire in the cyst. A fistulous tract was created using a needle knife or a 6 French cystotome (Endoflex $\mathrm{GmbH}$, Dusseldorf, Germany) followed by a $4 \mathrm{~mm}$ or $6 \mathrm{~mm}$ controlled radial expansion wire-guided balloon dilation. Stent delivery catheters for either the LAMS or BFMS were then placed over a guidewire and advanced into the WON. The distal flange was deployed under EUS guidance so that it was positioned against the WON wall. Deployment of the proximal flange was then performed under endoscopic guidance. The selection of stent diameter was at the discretion of the endoscopist. In patients with LAMS, the deployed stent lumen was then dilated up to the diameter of the stent with a controlled radial expansion balloon to allow for optimal stent luminal expansion.

\section{Patient follow up after procedure}

All patients were observed after the procedure with an overnight hospital admission. Broad spectrum intravenous antibiotics with 
the ability to penetrate pancreatic necrosis (e.g., carbapenems, quinolones, metronidazole) were continued for 2-3 days, after which the route was changed to oral. In patients with persistent or new onset symptoms, a non-contrast CT scan was carried out to assess the response to treatment and exclude any procedurerelated adverse events. Endoscopic reintervention was performed on patients who had refractory abdominal pain, persistent fevers, nausea/vomiting, or those with ongoing systemic inflammatory response syndrome even after initial stent placement.

Patients in the LAMS group who remained symptomatic without clinical improvement after $72 \mathrm{~h}$ underwent DEN. The necrotic cavity was entered transmurally via an endoscope at regular intervals until complete resolution of the necrotic cavity was confirmed endoscopically and/or by cross-sectional imaging. Irrigation of the WON cavity with $3 \%$ hydrogen peroxide during DEN was performed at the endoscopist's discretion.

Patients in the BFMS group were treated using a "step-up approach". As the first step in this approach, any occluding debris was cleared using endoscopic devices (de-clogging) using snare or forceps if there was no clinical improvement in the patient $72-96 \mathrm{~h}$ after initial BFMS placement. In patients who did not improve with de-clogging of the stent, the second step was to place an 8.5-Fr nasocystic tube (NCT) within the lumen of the WON and perform irrigation with saline and 3\% hydrogen peroxide (each session of irrigation was done at 8 hourly intervals using $20 \mathrm{~mL}$ of $3 \% \mathrm{H}_{2} \mathrm{O}_{2}$, followed $10 \mathrm{~min}$ later by $100 \mathrm{~mL}$ saline). Those without improvement then underwent the third step treatment, i.e., DEN. Subsequent sessions of DEN were dependent on the patients' symptoms.

All patients underwent imaging with a contrast-enhanced abdominal CT or transabdominal ultrasound at 4-8 weeks after initial stent placement, followed by an outpatient clinic visit. The stent was removed if complete WON decompression was achieved, i.e., the WON had completed resolved without leaving any residual fluid component. Patients were then followed at regular intervals for at least 6 months in an ambulatory setting after stent removal and repeat imaging was performed if there was any clinical suspicion of WON recurrence.

\section{Outcome measures}

The primary outcome of this study was to evaluate the clinical success rate of the LAMS and BFMS for therapy of WON at 6-month follow up, defined as: i) complete radiological resolution of WON; ii) no need for further treatment of the WON with percutaneous or surgical drainage; and iii) resolution of clinical symptoms. Secondary outcomes evaluated were technical success (ability to access and drain a WON by placement of transmural stents), adverse events (AEs), stent migration, stent dysfunction after placement, the number of endoscopic reinterventions required, and WON recurrence rates after stent removal.

Procedure-related AEs were defined as those that occurred within 7 days of the procedure. Major bleeding was defined as hemodynamic instability and/or bleeding in which endoscopic intervention was unsuccessful in obtaining hemostasis and which required embolization or surgical intervention. Minor bleeding was defined as bleeding that was controlled with endoscopic intervention. Procedure-related death was defined as death within $48 \mathrm{~h}$ of the procedure, or resulting from events directly related to the procedure. Information on all patients who died was collected. Long-term AEs (endoscopic reintervention because of stent dysfunction due to occluding debris and stent migration) were defined as AEs that occurred 7 or more days after the index stent placement procedure.

Stent migration was into divided in 2 types: clinically insignificant and clinically significant. Clinically insignificant migration was defined as spontaneous external migration of a stent after complete resolution of WON. Clinically significant migration was defined as stent migration that occurred before the WON had resolved, and could be either internal or external, as follows: internal migration was migration of the stent inside the WON cavity with persistent WON, whereas external migration was migration of the stent into the lumen with persistent WON.

\section{Statistical analysis}

This was a retrospective cohort study. We divided the subjects into 2 groups according to the type of stent used to drain the WON: 1) LAMS and 2) BFMS. Outcomes between the groups were compared using Student's $t$-test for continuous variables and the chi-square test for categorical variables. Generalized linear modeling (GLM) was performed on categorical and continuous variables in order to assess the impact of the stent type. All initial GLMs were univariate, with stent type as the only predictor. A multivariate GLM was also run in order to assess the impact of stent type in the presence of age, sex, WON size and short-term AEs as indicators of the odds of successful WON resolution. The Akaike information criterion was used to determine the most appropriate link function in the GLMs for each outcome. Statistical significance was determined a priori as $\mathrm{P} \leq 0.05$.

\section{Results}

\section{Baseline characteristics}

We evaluated 387 patients with symptomatic pancreatic WONs in whom EUS-guided drainage using either LAMS or BFMS was performed. The median age of the patients was 43 (range 11-87) years and 27\% were female. The overall etiologies of the patients' pancreatitis were gallstones (36.9\%), alcohol (39.5\%), idiopathic (17.3\%), and other causes $(6.72 \%)$. The WON were located in the head (8.3\%) or body and tail (90.9\%). The median size of the WON was 100 (range, 30-260) $\mathrm{mm}$. The patients and the WON characteristics of the 2 groups are 
Table 1 Patient demographics and pancreatic fluid collection characteristics

\begin{tabular}{|c|c|c|c|c|}
\hline Characteristics & All patients $\mathrm{N}=387$ & BFMS N=205 & LAMS N=182 & $\mathrm{P}$-value \\
\hline \multicolumn{5}{|l|}{ Sex } \\
\hline Female & 103 & $24(11.7 \%)$ & $79(43.4 \%)$ & \multirow[t]{2}{*}{$<0.0001$} \\
\hline Male & 284 & $181(88.3 \%)$ & $103(56.6 \%)$ & \\
\hline Mean age (years) & 43.6 & 34.8 & 53.4 & $<0.001$ \\
\hline \multicolumn{5}{|l|}{ Race } \\
\hline White & 143 & $0(0 \%)$ & $143(78.6 \%)$ & \multirow[t]{4}{*}{$<0.0001$} \\
\hline Black & 14 & $0(0 \%)$ & $14(7.7 \%)$ & \\
\hline Hispanic & 15 & $0(0 \%)$ & $15(8.2 \%)$ & \\
\hline Other & 215 & $205(100 \%)$ & $10(5.5 \%)$ & \\
\hline \multicolumn{5}{|l|}{ Pancreatitis etiology } \\
\hline Gallstone & 143 & $55(26.8 \%)$ & $88(48.4 \%)$ & \multirow[t]{7}{*}{$<0.0001$} \\
\hline Alcohol & 151 & $91(44.4 \%)$ & $60(33 \%)$ & \\
\hline Idiopathic & 67 & $52(25.4 \%)$ & $15(8.2 \%)$ & \\
\hline Trauma & 0 & $0(0 \%)$ & $0(0 \%)$ & \\
\hline Autoimmune & 2 & $0(0 \%)$ & $2(1.1 \%)$ & \\
\hline High triglycerides & 17 & $3(1.5 \%)$ & $14(7.7 \%)$ & \\
\hline Drug related & 7 & $4(2 \%)$ & $3(1.6 \%)$ & \\
\hline Mean WON long axis measurement (mm) & 112.9 & 108.7 & 117.7 & 0.0598 \\
\hline \multicolumn{5}{|l|}{ Site of WON } \\
\hline Pancreatic head & 32 & $24(11.7 \%)$ & $8(4.4 \%)$ & \multirow[t]{2}{*}{0.0105} \\
\hline Pancreatic body/tail & 352 & $181(88.3 \%)$ & $171(95.6 \%)$ & \\
\hline \multicolumn{5}{|l|}{ Stent characteristics } \\
\hline $\begin{array}{l}\text { Stent characteristics } \\
(\text { diameter } \times \text { length) }\end{array}$ & & $\begin{array}{c}29(14 \times 10 \mathrm{~mm}) \\
27(14 \times 20 \mathrm{~mm}) \\
106(16 \times 10 \mathrm{~mm}) \\
32(16 \times 20 \mathrm{~mm}) \\
11(14 \times 30 \mathrm{~mm})\end{array}$ & $\begin{array}{c}59(10 \times 10 \mathrm{~mm}) \\
122(15 \times 10 \mathrm{~mm}) \\
1(20 \times 10 \mathrm{~mm})\end{array}$ & \\
\hline
\end{tabular}

${ }^{\star}$ Statistically significant

BFMS, fully covered bi-flanged metal stent; LAMS, lumen-apposing metal stent; WON, pancreatic walled-off necrosis

Table 2 Procedural characteristics and adverse events

\begin{tabular}{lcc}
\hline Characteristics & BFMS N=205 & LAMS N=182 \\
\hline Site of cyst- enterostomy & $205(100 \%)$ & $119(65.4 \%)$ \\
$\quad$ Stomach & $0(0 \%)$ & $63(34.6 \%)$ \\
Duodenal bulb & 99 & 98.9 \\
Procedural technical success (\%) & $186(90.7 \%)$ & $162(89 \%)$ \\
Procedure-related adverse events & $2(1 \%)$ & $5(2.7 \%)$ \\
None & $15(7.3 \%)$ & $12(6.6 \%)$ \\
Clinically significant bleeding & $2(1 \%)$ & $3(1.6 \%)$ \\
Suprainfection & & 0.61 \\
Perforation & &
\end{tabular}

BFMS, fully covered bi-flanged metal stent; LAMS, lumen-apposing metal stent

summarized in Table 1. As compared to the LAMS group, patients in the BFMS group were significantly younger, mostly male, all Asian in ethnicity-due to the location of the center where BFMS was utilized-and had alcohol as the predominant etiology of pancreatitis.

\section{Procedure characteristics of initial EUS-guided WON drainage procedure}

A total of 182 patients underwent WON cavity drainage using LAMS and 205 had drainage using BFMS (Table 2). 
Table 3 Results of endoscopic ultrasound-guided drainage/debridement for WON

\begin{tabular}{|c|c|c|c|}
\hline Characteristics & BFMS N=205 & LAMS N=182 & P-value \\
\hline Mean number of endoscopic sessions for WON resolution & 1.54 & 2.71 & $<0.001$ \\
\hline \multicolumn{4}{|l|}{ Total number of endoscopic sessions after stent placement } \\
\hline 1 & $156(76.1 \%)$ & $38(20.9 \%)$ & $<0.0001$ \\
\hline 2 & $10(4.9 \%)$ & $64(35.1 \%)$ & \\
\hline$\geq 3$ & $39(19 \%)$ & $80(44 \%)$ & \\
\hline Success rate for endoscopic drainage of WON (\%) & $96.1 \%$ & $95.6 \%$ & 0.8078 \\
\hline Recurrence of WON after endoscopic stent removal (\%) & $2.4 \%$ & $0 \%$ & 0.25 \\
\hline
\end{tabular}

Trans-gastric drainage was performed in 324 patients (83.7\%), while 63 patients $(16.27 \%)$ had trans-duodenal drainage.

\section{Clinical success}

At 6-month follow up, overall clinical success with successful eradication of the WON was achieved in $95.6 \%$ patients with LAMS and $96.1 \%$ of patients with BFMS $(\mathrm{P}=0.80)$. Patients whose symptoms did not resolve with endoscopic therapy required additional interventions in the form of percutaneous or surgical drainage (Table 3). On multivariate analysis, the type of stent, age, sex and WON size did not predict the success of WON resolution (Table 4).

The median number of procedures required for WON resolution after initial stent placement was significantly lower with BFMS stents (2, range 2-5) compared to LAMS (3, range $2-8)(\mathrm{P}<0.001)$. Approximately $44 \%$ of patients with LAMS stents required 3 or more endoscopic sessions for DEN following stent placement in comparison to only $16.3 \%$ of patients with BFMS stents.

The LAMS were successfully removed once complete resolution of the WON had been confirmed by CT scan after a mean time of 26 (range 17-72) days. The BFMS were successfully removed after confirmation of complete resolution of WON by CT scan after a mean time of 37 days (range 14-87) days.

In the BFMS group, $162(72 \%)$ patients underwent stent removal after 4-8 weeks, 15 (7\%) patients had spontaneous migration of the BFMS into the gastric lumen due to complete resolution of the pancreatic WON, and 21 (10\%) reported for late removal of the BFMS for logistical reasons.

\section{Technical success}

There was no statistically significant difference in the overall technical success (ability to access and drain a WON by placement of transmural stents) between the LAMS and BFMS groups ( $98.9 \%$ vs. $99 \%$, respectively, $\mathrm{P}=0.9048$; Table 2). There was maldeployment of the LAMS in 2 patients.

Of the 2 patients with technical failure in the BFMS group, the first patient had a large WON with an entry point close to the gastroesophageal junction, posing a technical challenge to stent deployment, while the second patient had an internally
Table 4 Multivariate analysis evaluating predictors of success for WON resolution

\begin{tabular}{lcc}
\hline Predictors of Success & $\begin{array}{c}\text { Odds ratio } \\
(95 \% \mathrm{CI})\end{array}$ & P-value \\
\hline $\begin{array}{l}\text { Stent type } \\
\text { LAMS }\end{array}$ & Ref & 0.6795 \\
$\quad$ BFMS & $1.31(0.37-4.64)$ & \\
Age & $1.00(0.96-1.04)$ & 0.9764 \\
Sex & $0.59(0.15-2.30)$ & 0.4451 \\
WON size $(\mathrm{mm})$ & $1.00(0.99-1.01)$ & 0.5605 \\
Procedural adverse events & $1.13(0.31-4.15)$ & 0.8494 \\
\hline
\end{tabular}

${ }^{{ }^{*} \text { Statistically significant }}$

BFMS, fully covered bi-flanged metal stent; LAMS, lumen-apposing metal stent; WON, pancreatic walled-off necrosis; CI, confidence interval

migrated BFMS as the result of an obscured endoscopic view during deployment.

In the patients where LAMS were successfully deployed, the diameters of the stents were: $10 \mathrm{~mm}(\mathrm{n}=7)$ and $15 \mathrm{~mm}(\mathrm{n}=173)$. In the BFMS group, the stent diameters were: $12 \mathrm{~mm}(\mathrm{n}=3), 14$ $\mathrm{mm}(\mathrm{n}=98)$, and $16 \mathrm{~mm}(\mathrm{n}=104)$.

Patients with stent maldeployment were referred for drainage of their WON by either surgical or interventional radiology management.

\section{Procedure-related AEs (within 7 days of index procedure)}

In the LAMS group, procedure-related AEs occurred in 20 (10.9\%) patients. Five patients had major bleeding requiring abdominal angiography. Three patients developed perforation during the cyst-enterostomy requiring surgical closure. Suprainfection requiring intravenous antibiotics occurred in 12 patients.

In the BFMS group, procedure-related AEs occurred in 19 (9.3\%) patients. Two patients had major bleeding, with one requiring abdominal angiography and one needing surgery. Two patients developed perforation during the cyst-enterostomy requiring surgical closure. Suprainfection requiring intravenous antibiotics occurred in 15 patients.

Patients in the BFMS group had a similar rate of procedurerelated AEs compared to the LAMS group (9.3\% vs. $10.9 \%$, 
$\mathrm{P}=0.61$ ). On multivariate logistic regression analysis, there was no statistically significant difference between the stents as regards the risk of procedural AEs (odds ratio 1.13, $\mathrm{P}=0.84$ ), even after adjustment for sex, age and cyst size. These results are summarized in Table 2.

\section{Long-term AEs (7 or more days after index endoscopy)}

Long-term AEs (endoscopic reintervention because of stent dysfunction due to occluding debris and stent migration) were significantly more frequent in the BFMS group at $17.6 \%$ (36/205 patients) compared to the LAMS group at $7.7 \%(14 / 182$ patients; $\mathrm{P}=0.0039$ ).

\section{Stent dysfunction}

Stent dysfunction with occluding debris was significantly more common in the BFMS group compared to the LAMS group ( $10.2 \%$ and $5.9 \%$, respectively, $\mathrm{P}=0.04$ ).

\section{Endoscopic reintervention}

Endoscopic reintervention via DEN was performed in 151/182 (82.9\%) patients treated with a LAMS. Thirty-eight patients had one session, 64 had 2 sessions, and 49 had 3 or more sessions in order to achieve WON resolution. Hydrogen peroxide-assisted necrosectomy was performed in 37 of these patients.

In the BFMS group, reintervention was required in 49 (23.9\%) patients who had persistent symptoms after initial stent placement. Stent dysfunction with occluding debris was noted in 21 patients; 10 patients improved with de-clogging while 11 patients required NCT placement with irrigation, because of the presence of visible debris within the WON. Another 28 patients went directly to the second step of NCT placement, when infected debris within WON was noted without stent dysfunction. In total 39 patients required NCT irrigation, which was maintained for 3-7 days. After clinical improvement, a relook WON inspection was done and those patients who had healthy granulation tissue (observed in 10) with no significant debris had the NCT removed. Six patients with adherent mild debris required placement of a plastic stent within the BFMS. Another 23 patients (11.2\%) who did not improve with NCT and lavage required DEN.

\section{Stent migration}

The overall migration rate (significant and insignificant) was higher in the patients with BFMS $(\mathrm{n}=15)$ compared to those with LAMS ( $\mathrm{n}=3)(7.3 \%$ vs. $1.6 \%$; $\mathrm{P}=0.0008)$. However, there was no difference between the BFMS and LAMS groups in the clinically significant migration ( $2.4 \%$ vs. $1.6 \%$, respectively; $\mathrm{P}=0.73$ ). Stent migrations in the LAMS group occurred spontaneously and the stent passed without incident. All clinically significant migrations in the BFMS group occurred during DEN. Of these, 2 patients had internal migration into the WON and the BFMS stents were repositioned using grasping forceps. The other 3 patients had external migration and the stent was repositioned successfully into the WON using grasping forceps.

\section{Patient follow up}

Symptomatic PFC recurrence after stent removal occurred in no patients in the LAMS group compared to 5 patients in the BFMS group $(\mathrm{P}=0.25)$. All of these patients had a disconnected pancreatic duct and were treated successfully by EUS-guided drainage using plastic stents.

\section{Discussion}

EUS-guided drainage/debridement of WON using transmural stents is now the preferred modality for the treatment of pancreatic WON, because of its lower complication rates, and significantly lower morbidity and mortality when compared to surgery [5-7,20-22]. DPTs have historically been the first-line endoscopic accessory used in the endoscopic management of PFCs, including WON. There are, however, several inherent disadvantages to the use of DPTs in the management of WON, including their small diameter (7-10 Fr), high rates of stent occlusion and migration, and the need for multiple stent placements to obtain adequate drainage and debridement [9-11,23].

Limitations in the conventional accessories used to manage WON have led to the invention of specialized metal stents for PFC drainage. The "saddle-shaped" lumen-apposing fully covered metal stent $\left(\right.$ AXIOS $\left.^{\mathrm{m}}\right)$ and the bi-flanged metal stent $\left(\mathrm{NAGI}^{\mathrm{IN}}\right)$ are custom-made for debridement of PFCs and have been demonstrated to have a high success rate for the drainage/ debridement of WON $[15,17,18,24]$. Several studies to date have demonstrated the LAMS and BFMS to be safe and effective, with high rates of technical (89-100\%) and clinical success (77$100 \%)[13-15,17,19,25-28]$. A unique feature of these stents is that their unique design, with a large inner diameter, allows direct endoscopic debridement of WONs after stent deployment by passage of the standard endoscope through the stent lumen without stent removal; the anchoring flanges prevent stent dislodgement during the debridement. The LAMS is presently FDA approved in the United States for drainage of PFCs, while the BFMS stent is currently not available for use in the United States.

In a multicenter retrospective study, Siddiqui et al reported a technical success rate of $97.5 \%$ and $88 \%$ clinical success in WON drainage using LAMS [28]. Two cases of technical failure were due to stent maldeployment in the pancreatic pseudocyst group. Sharaiha et al, in a retrospective analysis of 124 patients with WON, achieved a clinical success rate of $86 \%$ of patients using the LAMS [17].

Equally high rates of clinic and technical success have been noted with the use of the BFMS in the management of PFCs, including WON. In a retrospective case series, Yamaoto et al reported on the use of the BFMS in the treatment of PFCs in 
9 patients (5 patients with pseudocysts and 4 patients with WON). Technical success was $100 \%$ and clinical success was achieved in $77.8 \%$. Drainage of pancreatic pseudocysts was achieved in all patients, while complete remission of infection was noted in $2 / 4$ patients $(50 \%)$ of patients with WON. There was 1 episode of internal stent migration thought to be due to complete resolution of the cyst. No stent-related complications were noted [27]. Chandran et al evaluated the role of BFMS in 47 patients with PFCs and reported a technical success rate of $98.1 \%$ and $76.6 \%$ clinical success (36/47 patients). The lower clinical success rate was attributed to a large subgroup of patients with WON, infected WON and infected pseudocyst. Notably, 34 of 36 patients (94.4\%) with successful resolution of PFCs showed a sustained response for more than 6 months [14].

In the present study we found similarly excellent technical success rates in patients with LAMS and BFMS (98.9\% vs. 99\%, $\mathrm{P}=0.9$ ). Technical failure was noted in 2 patients in both the LAMS and BFMS groups. Clinical success for WON drainage was not significantly different in the LAMS and BFMS groups (95.6\% vs. $96.1 \%, \mathrm{P}=0.8078$ ). During long-term follow up, 8 patients in each group required additional therapy in the form of surgical debridement or percutaneous catheter drainage because of failure of endotherapy.

DEN was performed in 151 patients in the LAMS cohort (82.9\%) compared to 23 patients in the BFMS cohort $(11.2 \%$ of total treated with BFMS). Patients in the LAMS group underwent a great number of DEN, since the management protocol in all these centers scheduled aggressive DEN until resolution of the WON. This was different from the management protocol in the BFMS cohort, where a step-up approach was adopted; DEN in these patients was only performed if other adjunctive interventions with de-clogging, nasocystic catheters and hydrogen peroxide were not successful [21,29].

The median number of procedures required for WON resolution after initial stent placement was significantly higher with LAMS compared to BFMS. The larger internal diameter of the BFMS may have been more effective for spontaneous WON drainage. Furthermore, DEN carried out through the wider BFMS may have been more effective for debris evacuation, obviating the need for additional endoscopic sessions. As noted above, the increased number of procedures required in the LAMS group may simply be a reflection of the protocol followed in these centers, where the endoscopists believed in scheduled aggressive DEN.

The most frequent AEs associated with endoscopic drainage and DEN in patients with WON are bleeding, perforation or post-procedure infection [30]. Despite the unique anchoring design, intended to ensure firm anchorage, there have been reports of stent migration and dislodgement reported with both the LAMS and BFMS $[25,26]$. Rinninella and Shah each reported one case of stent migration with LAMS [26,31]. Ang et al observed a high stent migration rate (6.3\%) with BFMS; they postulated that the high risk of migration with BFMS may be due to a lack of lumen apposition and excessive length. Similarly, in our study, stent migration was higher in the BFMS cohort, although in the majority of cases it was not clinically significant. Spontaneous migration in the LAMS was not associated with AEs. All migrations in the BFMS happened during DEN.
Our study showed that patients in the BFMS group had a significantly higher rate of stent occlusion with debris compared to the LAMS group. This difference may reflect an inherent disadvantage with the step-up approach used in the BFMS cohort, as compared to DENs after a planned interval in the LAMS cohort (during which any debris partially occluding the stent would have been removed). Our study shows similar results to those of Bekkali et al [35], where LAMS were superior to BFMS in terms of procedure time, with comparable AEs and success.

In our study, external stent migration was noted in $3 / 182$ (1.65\%) patients in the LAMS group and 5/205 (2.4\%) patients with BFMS stents. This incidence is consistent with other studies. Bapaye et al recently reported a migration rate of $2.7 \%$ in patients with BFMS. In the present study, procedural AEs were similar in the LAMS group $(20 / 182 ; 11 \%)$ and the BFMS group (19/205; 9.3\%) Previous studies have reported similar complications with the use of BFMS [16, 24,32,33]. Significant bleeding was higher in the LAMS cohort as compared to the BFMS group. While bleeding at the time of stent deployment or within the following week is difficult to explain, since all these procedures were done under EUS Doppler guidance, this could be related to stent erosion into a vessel as the WON cavity wall collapses, or a pseudoaneurysm in the cavity wall.

Our study has several strengths. Thus far the majority of available literature on the use of the specialized BFMS, customized for management of PFCs, have been singlearm non-comparative case series reporting efficacy for all PFCs, including pseudocyst and WON, in small groups of patients. Our study is the only one to date that has performed a comparison, evaluating the efficacy and safety of lumenapposing LAMS and BFMS in patients with WON.

The present study does have a number of limitations. It was retrospective in nature, with its inherent limitations including variable follow up of patients, quality of crosssectional imaging at different centers and variability in the technique of the endoscopist. In addition, the BFMS were used in one center in India, while the LAMS were used in centers in the USA; hence the patients studied had different demographic characteristics. As the subjects in each cohort were not from the same representative sample, there was significant heterogeneity between the 2 groups. We also did not have data on the percentage of solid debris in the WON cavity, which could potentially influence procedural success.

The optimal stent for endoscopic drainage of WON remains unsettled. Several authors have argued that, based on the current literature, there are insufficient data to support the routine use of one stent type over another [34]. With the advent of new stents such as the LAMS and BFMS, customized for PFC drainage, there may be a trend toward using these stents especially in the management of WON when necrosectomy is required. In this study we have demonstrated that endoscopic therapy of WON using either LAMS with scheduled DEN and BFMS using a step-up approach is safe and equally effective in terms of overall treatment efficacy. Further randomized controlled studies are needed to confirm these results and investigate the long-term results, cost-effectiveness and complication rates of these stents. 


\section{Summary Box}

\section{What is already known:}

- Fully covered bi-flanged metal stents (BFMS) and lumen-apposing metal stents (LAMS) have both been shown in individual clinical trials to be safe and effective for endoscopic ultrasound-guided drainage of pancreatic walled-off necrosis

\section{What the new findings are:}

- In this unique retrospective clinical study that directly compared the clinical outcomes and adverse events of the BFMS and LAMS, the clinical success and adverse events in the BFMS and LAMS groups were similar

- Stent migration rate for BFMS was significantly higher compared to LAMS

\section{References}

1. Gerolami R, Giovannini M, Laugier R. Endoscopic drainage of pancreatic pseudocysts guided by endosonography. Endoscopy 1997;29:106-108.

2. Panamonta N, Ngamruengphong S, Kijsirichareanchai K, Nugent K, Rakvit A. Endoscopic ultrasound-guided versus conventional transmural techniques have comparable treatment outcomes in draining pancreatic pseudocysts. Eur J Gastroenterol Hepatol 2012;24:1355-1362.

3. Gardner TB, Coelho-Prabhu N, Gordon SR, et al. Direct endoscopic necrosectomy for the treatment of walled-off pancreatic necrosis: results from a multicenter U.S. series. Gastrointest Endosc 2011;73:718-726.

4. Banks PA, Bollen TL, Dervenis C, et al; Acute Pancreatitis Classification Working Group. Classification of acute pancreatitis--2012: revision of the Atlanta classification and definitions by international consensus. Gut 2013;62:102-111.

5. Gardner TB, Chahal P, Papachristou GI, et al. A comparison of direct endoscopic necrosectomy with transmural endoscopic drainage for the treatment of walled-off pancreatic necrosis. Gastrointest Endosc 2009;69:1085-1094.

6. Baron TH, Thaggard WG, Morgan DE, Stanley RJ. Endoscopic therapy for organized pancreatic necrosis. Gastroenterology 1996;11: 755-764.

7. Bakker OJ, van Santvoort HC, van Brunschot S, et al; Dutch Pancreatitis Study Group. Endoscopic transgastric vs surgical necrosectomy for infected necrotizing pancreatitis: a randomized trial. JAMA 2012;307:1053-1061.

8. Kumar N, Conwell DL, Thompson CC. Direct endoscopic necrosectomy versus step-up approach for walled-off pancreatic necrosis: comparison of clinical outcome and health care utilization. Pancreas 2014;43:1334-1339.

9. Krüger M, Schneider AS, Manns MP, Meier PN. Endoscopic management of pancreatic pseudocysts or abscesses after an EUSguided 1-step procedure for initial access. Gastrointest Endosc 2006;63:409-416.

10. Lopes CV, Pesenti C, Bories E, Caillol F, Giovannini M. Endoscopic- ultrasound-guided endoscopic transmural drainage of pancreatic pseudocysts and abscesses. Scand J Gastroenterol 2007;42:524-529.

11. Varadarajulu S, Tamhane A, Blakely J. Graded dilation technique for EUS-guided drainage of peripancreatic fluid collections: an assessment of outcomes and complications and technical proficiency (with video). Gastrointest Endosc 2008;68:656-666.

12. Seewald S, Ang TL, Kida M, Teng KY, Soehendra N; EUS 2008 Working Group. EUS 2008 Working Group document: evaluation of EUS-guided drainage of pancreatic-fluid collections (with video). Gastrointest Endosc 2009;69:S13-S21.

13. Bapaye A, Itoi T, Kongkam P, Dubale N, Mukai S. New fully covered large-bore wide-flare removable metal stent for drainage of pancreatic fluid collections: results of a multicenter study. Dig Endosc 2015;27:499-504.

14. Chandran S, Efthymiou M, Kaffes A, et al. Management of pancreatic collections with a novel endoscopically placed fully covered self-expandable metal stent: a national experience (with videos). Gastrointest Endosc 2015;81:127-135.

15. Itoi T, Nageshwar Reddy D, Yasuda I. New fully-covered selfexpandable metal stent for endoscopic ultrasonography-guided intervention in infectious walled-off pancreatic necrosis (with video). J Hepatobiliary Pancreat Sci 2013;20:403-406.

16. Mukai S, Itoi T, Sofuni A, Tsuchiya T, Gotoda T, Moriyasu F. Clinical evaluation of endoscopic ultrasonography-guided drainage using a novel flared-type biflanged metal stent for pancreatic fluid collection. Endosc Ultrasound 2015;4:120-125.

17. Sharaiha RZ, Tyberg A, Khashab MA, et al. Endoscopic therapy with lumen-apposing metal stents is safe and effective for patients with pancreatic walled-off necrosis. Clin Gastroenterol Hepatol 2016; 14:1797-1803.

18. Siddiqui AA, Adler DG, Nieto J, et al. EUS-guided drainage of peripancreatic fluid collections and necrosis by using a novel lumen-apposing stent: a large retrospective, multicenter U.S. experience (with videos). Gastrointest Endosc 2016;83:699-707.

19. Gornals JB, De la Serna-Higuera C, Sánchez-Yague A, Loras C, Sánchez-Cantos AM, Pérez-Miranda M. Endosonography-guided drainage of pancreatic fluid collections with a novel lumenapposing stent. Surg Endosc 2013;27:1428-1434.

20. Baron TH, Morgan DE. Endoscopic transgastric irrigation tube placement via PEG for debridement of organized pancreatic necrosis. Gastrointest Endosc 1999;50:574-577.

21. Siddiqui AA, Dewitt JM, Strongin A, et al. Outcomes of EUSguided drainage of debris-containing pancreatic pseudocysts by using combined endoprosthesis and a nasocystic drain. Gastrointest Endosc 2013;78:589-595.

22. Varadarajulu S, Wilcox CM, Latif S, Phadnis M, Christein JD. Management of pancreatic fluid collections: a changing of the guard from surgery to endoscopy. Am Surg 2011;77:1650-1655.

23. McVay T, Adler DG. EUS-guided drainage of pancreatic fluid collections: Double pigtails, metal biliary, or dedicated transluminal stents? Endosc Ultrasound 2015;4:1-3.

24. Lakhtakia S, Basha J, Talukdar R, et al. Endoscopic "step-up approach" using a dedicated bi-flanged metal stent reduces the need for direct necrosectomy in walled-off necrosis (with videos). Gastrointest Endosc 2016;85:1243-1252.

25. Itoi T, Binmoeller KF, Shah J, et al. Clinical evaluation of a novel lumen-apposing metal stent for endosonography-guided pancreatic pseudocyst and gallbladder drainage (with videos). Gastrointest Endosc 2012;75:870-876.

26. Shah RJ, Shah JN, Waxman I, et al. Safety and efficacy of endoscopic ultrasound-guided drainage of pancreatic fluid collections with lumen-apposing covered self-expanding metal stents. Clin Gastroenterol Hepatol 2015;13:747-752.

27. Yamamoto N, Isayama H, Kawakami H, et al. Preliminary report on a new, fully covered, metal stent designed for the treatment of 
pancreatic fluid collections. Gastrointest Endosc 2013;77:809-814.

28. Siddiqui AA, Kowalski TE, Loren DE, et al. Fully covered selfexpanding metal stents versus lumen-apposing fully covered selfexpanding metal stent versus plastic stents for endoscopic drainage of pancreatic walled-off necrosis: clinical outcomes and success. Gastrointest Endosc 2016;85:758-765.

29. Abdelhafez M, Elnegouly M, Hasab Allah MS, Elshazli M, Mikhail HM, Yosry A. Transluminal retroperitoneal endoscopic necrosectomy with the use of hydrogen peroxide and without external irrigation: a novel approach for the treatment of walledoff pancreatic necrosis. Surg Endosc 2013;27:3911-3920.

30. Ruiz-Clavijo D, de la Higuera BG, Vila JJ. Advances in the endoscopic management of pancreatic collections. World $J$ Gastrointest Endosc 2015;7:381-388.

31. Rinninella E, Kunda R, Dollhopf M, et al. EUS-guided drainage of pancreatic fluid collections using a novel lumen-apposing metal stent on an electrocautery-enhanced delivery system: a large retrospective study (with video). Gastrointest Endosc 2015;82:1039-1046.

32. Mukai S, Itoi T, Baron TH, et al. Endoscopic ultrasound-guided placement of plastic vs. biflanged metal stents for therapy of walled-off necrosis: a retrospective single-center series. Endoscopy 2015;47:47-55.

33. Bapaye A, Dubale NA, Sheth KA, et al. Endoscopic ultrasonography-guided transmural drainage of walled-off pancreatic necrosis: comparison between a specially designed fully covered bi-flanged metal stent and multiple plastic stents. Dig Endosc 2016;29:104-110.

34. Bang JY, Varadarajulu S. Metal versus plastic stent for transmural drainage of pancreatic fluid collections. Clin Endosc 2013;46:500-502.

35. Bekkali NLH, Nayar MK, Leeds JS, Charnley RM, Huggett MT, Oppong KW. A comparison of outcomes between a lumenapposing metal stent with electrocautery-enhanced delivery system and a bi-flanged metal stent for drainage of walled-off pancreatic necrosis. Endosc Int Open 2017;5:E1189-E1196. 